\title{
EDUCAÇÃO ESCOLAR, SABERES CULTURAIS E PRÁTICAS EDUCATIVAS DOS REZADORES DE ALMAS NA AMAZÔNIA
}

\author{
EDUCACIÓN ESCOLAR, SABERES CULTURALES Y PRÁCTICAS \\ EDUCATIVAS DE LOS “REZADORES DE ALMAS” EN AMAZONIA.
SCHOOL EDUCATION, CULTURAL KNOWLEDGE AND EDUCATIONAL PRACTICES USED BY SOUL PRAYERS IN THE AMAZON

\author{
Raimundo Nonato de Pádua CÂNCIO ${ }^{1}$ \\ Sônia Maria da Silva ARAÚJO²
}

RESUMO: Ao partir do pressuposto de que a escola tem produzido a exclusão daqueles grupos cujos universos culturais não correspondem aos dominantes, baseados na perspectiva de uma educação multicultural e no estudo do tipo etnográfico realizado com os Rezadores de Almas do município de Oriximiná-PA, grupo que desenvolve o ritual secular de Encomendação das Almas, na Semana Santa, a presente pesquisa buscou responder como esses sujeitos expressam sua preocupação com a manutenção de seus saberes e de suas práticas culturais; qual a importância atribuída à escola na perpetuação desses saberes e qual tem sido o papel desta na preservação desse ritual. Os resultados revelam a indiferença com essa manifestação cultural e demonstram que os muros das escolas ainda são os limites com os demais saberes ditos não-escolares.

PALAVRAS-CHAVE: Educação. Saberes. Práticas culturais. Rezadores de Almas.

RESUMEN: Partiendo de la premisa de que la escuela ha producido la exclusión de aquellos grupos cuyos universos culturales no corresponden a los dominantes, basados en la perspectiva de una educación multicultural y en el estudio del tipo etnográfico realizado con los "Rezadores de Almas" de la ciudad de Oriximiná-PA, grupo que desarrolla el ritual secular de "Recomendación" de las Almas, en la Semana Santa, la presente investigación buscó contestar como esos sujetos expresan su preocupación con la manutención de sus saberes y de sus prácticas culturales; cuál la importancia asignada a la escuela en la perpetuación de esos saberes y cuál ha sido el papel de ésta en la preservación de ese ritual. Los resultados revelan la indiferencia con esa manifestación cultural y demuestran que los muros de las escuelas todavía son los limites con los otros saberes dichos no-escolares.

PALABRAS CLAVE: Educación. Saberes. Prácticas culturales. "Rezadores de Almas".

\footnotetext{
${ }^{1}$ Doutorando em Educação pela Universidade Federal do Pará, na Linha Educação, Cultura e Sociedade; Mestre em Educação pela Universidade do Estado do Pará; Licenciado Pleno em Letras (Língua Portuguesa) pela Universidade Federal do Pará. nonatocancio@ hotmail.com

${ }^{2}$ Doutora em Educação pela Universidade de São Paulo (USP), com pós-doutoramento pelo Centro de Estudos Sociais (CES) da Universidade de Coimbra. Coordenadora do Programa de Pós-graduação em Educação da Universidade Federal do Pará.
} 
ABSTRACT: In assumingthatthe school hasproduced the exclusion of groups whose cultural backgrounds do not match the prevailing, based on the perspective of multicultural education and the study of ethnographic performed with thechantersofthe municipality ofSoulsOriximiná-PA, group develops the secular ritual of commendation of Souls, Holy Week, this research sought to answer how these individuals expresstheir concernwith maintaining their knowledgeand their cultural practices, whichas signedto the schoolin the perpetuation of such know ledgeand what importance has be enthe role of the preservation of this ritual. The results show indifference to this cultural eventand demonstrate that the school walls are stilllimitsto the othernon-school know ledgesaid. KEY-WORDS: Education. Knowledge. Cultural practices. Chantersof Souls.

\section{Introdução}

Os paradigmas educativos que prefiguram a instituição escolar e que se estendem até nossos dias experimentam uma profunda crise e são objetos de variadas tentativas de transformação e reforma. Nesse contexto de mudanças, a escola assenta-se em ideias de justiça, igualdade e distribuição de saberes, entendidos aqui como bens culturais, para a criação de um sujeito histórico nacional, autônomo e livre. A ênfase a partir de agora deverá estar na aprendizagem, não no ensino, na construção do saber, não na instrução por meio dos conhecimentos produzidos pelos centros hegemônicos. Dito isto, parte-se do pressuposto de que é preciso conhecer e atribuir significados às coisas para que, posteriormente, seja possível situá-las na construção do conhecimento.

Moraes (1997, p. 178) entende que o significado emerge do contexto e da cultura, esta compreendida como um sistema de símbolos e significados e das conexões decorrentes dessas relações. Então, para a autora, não se pode subestimar as influências culturais e contextuais no desenvolvimento das inteligências humanas, pois são o próprio contexto e a cultura que avaliam, valorizam ou determinam a adequação deste ou daquele produto simbólico. Destaca ainda que examinar o contexto significa perceber a ecologia de tudo, compreender que as coisas só farão sentido se estiverem relacionadas umas com as outras, se estiverem interligadas, ou seja, em processo de interação constante.

Ao dar ênfase à importância do contexto, Moraes observa que a educação para ser válida necessita ser contextualizada e que a cultura, o contexto, os fatores históricoculturais, além dos biológicos e pessoais, influenciam o desenvolvimento das capacidades humanas. Nesse sentido, entende-se que a relação cultura-educação faz-se fundamental para o amadurecimento do indivíduo e que os saberes e as práticas 
culturais de cada sociedade são essenciais para a construção do conhecimento a respeito de si, de sua comunidade e dos outros sujeitos que a compõem.

A partir dos eixos de preocupações explicitados e em busca de subsídios para o desenvolvimento da sensibilização intercultural na escola, por meio de uma prática mais sensível, crítica e reflexiva, a presente pesquisa procurou responder a seguinte pergunta: como os Rezadores de Almas de Oriximiná expressam sua preocupação com a manutenção dos saberes $^{3}$ e de suas práticas culturais naquele contexto, e qual a importância atribuída por eles à escola para a preservação desse ritual?

Para responder a esta interrogação, buscou-se um referencial fundamentado na interlocução entre cultura e educação, como pontos indissociáveis e importantes no processo de construção do conhecimento, dentre os quais destaca-se Hall (1997), Imbernón (2000), Sacristán (2002), Charlot (2000) e outros, que contribuem para a reflexão acerca da constituição da escola em meio a uma trama de diferenças culturais, organizações sociais, comunidades locais, religiosidades e diferenças étnicas.

Trata-se de um Estudo de Caso do Tipo Etnográfico, cuja abordagem é qualitativa ${ }^{4}$. Este tipo de estudo utiliza um conjunto de técnicas para coletar dados sobre os valores, os hábitos, as crenças, as práticas e os comportamentos de um grupo social (ANDRÉ, 1995, p.27-28). Lüdke e André (1986, p. 18) definem que “os estudos de caso enfatizam a interpretação em contexto", o que irradia para uma busca em retratar concisamente a realidade em questão. Na educação, isso significa "um estudo em profundidade de um fenômeno educacional, com ênfase na singularidade e levando em conta os princípios do método da etnografia" (ANDRÉ, 2005, p. 19). Essa busca, consequentemente, gerou uma variedade de dados e fontes de informação, resultantes de um envolvimento direto com o objeto de estudo. A pesquisa foi realizada no município de Oriximiná-PA com dois Rezadores, conhecidos tradicionalmente como Encomendadores de Almas, os quais rezam na Semana Santa pelas almas condenadas.

\section{Diversidade sociocultural e desafios da escola}

Ao longo dos anos, o fato de o Brasil ter possuído uma religião oficial, o Catolicismo, fez com que os seguidores de outras denominações religiosas sofressem

${ }^{3}$ Constituem produções coletivas, já que "o saber é produzido pelo sujeito confrontado a outros sujeitos" (CHARLOT, 2000, p.61).

${ }^{4} \mathrm{O}$ enfoque qualitativo se vale de instrumentos e técnicas que permitam a descrição densa de um fato, a recuperação do sentido, com base nas manifestações do fenômeno e na recuperação dos contextos de interpretação (LÜDKE, 2001, p. 47). 
discriminação, sendo obrigados a desempenhar seus atos religiosos em espaços privados (GABATZ, 2012, p. 54). Com o advento da República, o país torna-se um Estado laico, ou seja, deixa de ter uma religião oficial e separa-se institucionalmente da Igreja (DEHER, 2005, p.51).

A Constituição Brasileira de 1988 instituiu como direito e dever individual e também coletivo que todos os cidadãos seriam iguais perante a lei, sem distinção de qualquer natureza. E, de igual forma, recomendou no seu artigo quinto que "é inviolável a liberdade de consciência e de crença, sendo assegurado o livre exercício dos cultos religiosos e garantida, na forma da lei, a proteção aos locais de culto e a suas liturgias" (BRASIL, 1988).

A liberdade de crença, portanto, e o livre exercício de cultos religiosos supõe o direito de cada um realizar a sua escolha religiosa. Supõe também a garantia do direito de que nas escolas sejam viabilizadas atitudes que permitam compreender as diferentes matrizes religiosas enquanto fenômenos presentes no desenrolar dos acontecimentos da humanidade em diversas culturas e tradições. No entanto, as manifestações de intolerâncias e de desrespeitos às diversidades culturais e religiosas têm sido cada vez mais frequentes neste país.

Ao relacionarmos esta discussão ao papel da escola, uma questão importante que precisa ser evidenciada, segundo Gabatz (2012, p. 55), é que esta instituição precisa se preocupar em conhecer as diversas expressões religiosas para que os alunos conheçam as suas próprias crenças e consigam situá-las em relação a outras", tendo em vista a convivência fraterna e pacífica. Acredita-se que o diálogo ecumênico e inter-religioso possa mobilizar o respeito às diferenças, se "vinculado a um compromisso moral e ético para suscitar preceitos de justiça, amor e paz" (Ibid, 2012, p. 55).

Ao refletir sobre a relação dos sujeitos com os saberes, Charlot (2000, p. 61-63) observa que a ideia de saber implica a de sujeito, de atividade do sujeito, de relação do sujeito com ele mesmo, de relação desse sujeito com outros que co-constroem, controlam, validam e partilham esse saber. Para ele, o saber é construído em uma história coletiva que é a da mente humana e das atividades do homem e está submetido a processos coletivos de avaliação, capitalização e transmissão. $\mathrm{O}$ autor destaca ainda que analisar a relação com o saber é estudar o sujeito confrontado à obrigação de aprender, em um mundo que ele partilha com outros: a relação com o saber é, portanto, relação com o mundo, relação consigo mesmo, relação com os outros (Ibid., 2000, p. 79). 
No entanto, cabe considerar que há relações de forças nos saberes socialmente institucionalizados, como naqueles ensinados nas escolas, razão pela qual alguns saberes são mais ou menos difundidos em determinada sociedade. É bastante comum observamos atitudes de rejeição e exclusão a alguns grupos, as quais se manifestam em preconceitos, humilhações e violências impostas aos inferiorizados. As relações com o diferente geralmente se traduzem em "discriminações socialmente propagadas e opiniões distorcidas", e podem formar em nossa mente julgamentos apressados e rigidez de pensamento (INCONTRI; BIGHETO, 2005, p.4).

Nesse sentido, importa entender que as diferenças de cada cultura são explicadas pela história cultural de cada grupo. E, sob este pensamento, não há lugar para discriminação e nem hierarquização de valores e princípios, pois as culturas não devem ser hierarquizadas, uma vez que cada uma possui características peculiares. É nesse universo cultural complexo que a escola é chamada a possibilitar ao educando a compreensão da dinâmica cultural na humanidade, haja vista que, conforme Hall (1997, p. 18),

A ação social é significativa tanto para aqueles que a praticam quanto para os que a observam: não em si mesma, mas em razão dos muitos e variados sistemas de significado que os seres humanos utilizam [...]. Estes sistemas ou códigos de significado dão sentido às nossas ações. Eles nos permitem interpretar significativamente as ações alheias. Tomados em seu conjunto, eles constituem nossas "culturas". Contribuem para assegurar que toda ação social é "cultural", que todas as práticas sociais expressam ou comunicam um significado e, neste sentido, são práticas de significação.

A respeito das práticas culturais de significação, é conveniente esclarecer que esta noção não deve ser pensada apenas em relação às instituições oficiais de produção cultural, mas também aos usos e costumes que caracterizam qualquer espaço social. São também práticas culturais as manifestações inscritas nas variações de comportamentos e atitudes de determinado grupo social. Nessa perspectiva, diz-se que o saber cotidiano está vinculado à prática do sujeito. Então a noção de saber possui relação com a noção de prática, e esta última, para Charlot (2000, p. 63), mobiliza informações, conhecimentos e saberes. Portanto, é necessário entender e exato afirmar que há saber nas práticas.

Para o mesmo autor, a heterogeneidade existe nas escolas porque existe na vida social externa. Todavia, a educação ajuda a produzir as diferenças ou acentuar algumas delas, haja vista que os docentes são agentes da diversificação, homogeneização, 
equiparação e das desigualdades produzidas nestas instituições. Isto leva-nos a concluir que desvendar o mundo dos significados da diversidade ou da diferença e ver o que se quis fazer com elas é o caminho para descobrir práticas, afinar objetivos, tomar consciência e poder administrar os processos de mudança de maneira mais reflexiva.

Dito isto, o conceito de cultura aqui abordado é aquele que se aproxima das ideias de Geertz (1973, p. 15), para o qual cultura é um padrão historicamente transmitido de significados encarnados em símbolos, um sistema de concepções herdadas, expressas em forma simbólica por meio das quais os homens comunicam, perpetuam e desenvolvem conhecimentos e atitudes em relação à vida. A cultura, portanto, onde transitam os saberes e as práticas, é uma construção que permanece como uma realidade consistente e significativa, decorrente da organização abrangente de rituais e sistemas simbólicos. Destaca ainda o autor que estes símbolos podem ser verbais e não-verbais e estão geralmente ligados ao ethos filosófico da cultura dominante (MCLAREN, 1991).

Com base neste ponto de vista, a cultura pode também ser definida como lugar onde as identidades são criadas, recriadas, modificadas e apresentadas (HALL, 2003). Assim como espaço de construção das lutas históricas, de relações sociais de dominação, resistências às formas e conteúdos de subalternização, de conciliações e acomodações com as dominações, típicas das operações humanas que se dão pelas relações de poder (CASTELL'S, 2001). No que se refere à cultura e às relações de poder que se entrecruzam nos espaços educativos, pode-se dizer que o confronto com os variados saberes que se renovam ao longo da história podem ajudar os docentes a superarem preconceitos.

No entanto, conforme Moreira e Candau (2005, p. 39),

Construir o currículo com base nessa tensão não é tarefa fácil e irá certamente requerer do professor nova postura, novos saberes, novos objetivos, novos conteúdos, novas estratégias e novas formas de avaliação. Será necessário que o docente se disponha e se capacite a reformular o currículo e a prática docente com base nas perspectivas, necessidades e identidades de classes e grupos subalternizados.

Em contraposição, percebe-se que as práticas educativas desenvolvidas na instituição escolar ainda desconsideram os saberes não escolares, aqueles que “convivem" na mesma comunidade, mas muitas vezes são ignorados pelos currículos instituídos. Sobre esta questão, Sacristán (2002, p. 13) comenta que as políticas e as práticas em favor da igualdade podem anular a diversidade, o que pode levar a 
instituição educacional a se isolar e se constituir como um universo sagrado, separado, propondo uma cultura também sagrada e distante da experiência de vida de seus alunos.

Cabe observar que no momento em que se discute a pluralidade cultural, e já se dispõe de uma proposta de inclusão desta temática como eixo transversal nos Parâmetros Curriculares Nacionais (PCN), precisa-se avançar no sentido de fazer dialogar uma perspectiva intercultural ${ }^{5}$ crítica, inclusive na formação docente, para que o professor passe a conviver e sinta-se mais seguro diante dos novos desafios.

Nesse sentido, conforme Sacristán (2002, p. 18), as práticas educativas, sejam as da família, das escolas ou de qualquer outro agente, deparam-se com a diversidade como um dado da realidade. Observa ainda que as formas de organização escolar e das práticas de ensino, como ocorre com a política para toda a sociedade, têm o desafio de salvaguardar o comum. Para o autor, isso implica renúncias individuais, aceitação de padrões compartilhados e a proteção de tudo que, sendo singular, possa ser definido eticamente e seja enriquecedor tanto para o indivíduo quanto para a comunidade social.

Sobre o ritual ${ }^{6}$ secular de Encomendação das Almas, realizado na Semana Santa no município de Oriximiná, O’Dwyer (2007, p. 105), em suas pesquisas na região do médio amazonas paraense, constatou que há influência da pajelança e de manifestações religiosas de origem africana nas cidades, e que estas também ocorrem na zona rural. Verificou que os ribeirinhos e a população de origem africana neste contexto constituem "unidades em contraste", ou seja, eles "se consideram diferentes em termos de subsistência e das interações que promovem no núcleo urbano" (Ibid., 2007, 100). Com isso, torna-se complexo identificar a que grupos identitários pertencem os atores sociais do ritual de Encomendação das Almas. No entanto, Soares (2010, p. 5) evidenciou que neste ritual "notam-se aspectos de diferentes culturas - negra, indígena, portuguesa, amazônica - e essa confluência, essa mistura, esse 'branchement' (Amselle) é que caracteriza o ritual”.

As pesquisas já realizadas sobre mostraram que tal religiosidade "está relacionada às práticas medievais europeias e com as mais remotas ideias advindas do paganismo" (COSTA, 2012, p. 27). Sendo assim, para a Igreja Católica e para as instituições sociais, dentre elas a escola, esse ritual traduz uma "concepção religiosa da visão da agonia, da

${ }^{5}$ Termo utilizado pelos franceses que, ao contrário dos anglo-saxões, como distinto de multiculturalismo, tenta expressar de forma mais progressista a relação com a diferença, ao enfatizar, pelo prefixo inter, o sentido de interação e troca, e não apenas de diversidade (SANTOS; LOPES, 1997).

6 Utiliza-se o termo ritual neste estudo para designar o conjunto de práticas que constituem a Encomendação das Almas na Semana Santa. 
morte e do post-mortem". E tal pensamento faz com que na atualidade o referido ritual seja concebido naquele contexto como uma manifestação impura, não-cristã, fundada nas tradições indígenas das Américas e nas tradições dos povos de origem africana.

Ao considerar estes aspectos mais gerais que caracterizam a Encomendação das Almas, Costa (2012, p. 29) entende que "é nesta perspectiva de aprendizagem da vida cotidiana, dos saberes da tradição e da oralidade que o Ritual de Encomendação das Almas está inserido", e que este deve ser levado às escolas, "pois a cultura que emerge deste ritual pode ser considerada um patrimônio imaterial transmitido entre as gerações". Trata-se, portanto, de pensar a educação escolar para além dos saberes institucionalizados, permitindo que aqueles saberes que foram colocados à margem e silenciados no cotidiano da região amazônica sejam desvelados, para que os sujeitos possam interpretar os fatos históricos e também compreender o mundo a partir de seus próprios saberes.

\section{Saberes e as Práticas Culturais dos Rezadores de Almas de Oriximiná}

Campo de atuação desta pesquisa, a cidade de Oriximiná está localizada ao longo da margem esquerda do rio Trombetas ${ }^{7}$, na região Oeste do Estado do Pará. A versão mais recorrente é a de que a fundação da cidade ocorreu quando o padre José Nicolino de Souza, em visita às congregações religiosas da região, dirigiu-se ao rio Nhamundá ${ }^{8} \mathrm{e}$ ao rio Trombetas para propagar, na versão da Igreja Católica, a fé cristã e a conversão das populações indígenas e ribeirinhas da região. No entanto, o historiador Márcio Couto Henrique observa que "a ideia de que José Nicolino de Sousa, com terçado em punho, desbravou as terras "virgens" que hoje constituem a cidade de Oriximiná constitui o mito de origem do lugar" (HENRIQUE, 2015, p. 50).

Pode-se dizer, com isso, que a história da fundação deste município sempre esteve atrelada à tradição religiosa propagada pela Igreja Católica. A ideia do padre heróifundador revela na verdade uma tentativa de afirmação da Igreja de se estabelecer na região com certo autoritarismo diante dos grupos indígenas, população de origem africana e ribeirinhos, pois para a instituição religiosa essas populações reagiam com certa instabilidade à civilização e à fé católica. Tal fato pode ser observado no estudo de

${ }^{7}$ Afluente pela margem esquerda do rio Amazonas.

${ }^{8} \mathrm{O}$ Nhamundá (ou Jamundá) é o rio onde, segundo a lenda, vivia a tribo das amazonas. Os primeiros navegadores dessa região descreveram as índias como uma tribo de mulheres guerreiras que montavam cavalos e manejavam a flecha com destreza. 
Henrique (2015) acerca da trajetória do padre José Nicolino, quando da especulação de que seu aprendizado tenha sido "superficial", haja vista ter fraquejado quando em contato com sua gente e seu meio:

\begin{abstract}
Muito embora tenha obtido o título de doutor em teologia e direito canônico, o índio teria renunciado ao Cristianismo e aos "hábitos de cultura e civilização que adotara". No fundo, prevalece a ideia de que seu aprendizado foi apenas superficial, compondo o quadro de uma exterioridade com a qual ele não se identificava e que sucumbiu ao primeiro contato com "sua gente e seu meio" (HENRIQUE, 2015, p. 49).
\end{abstract}

Havia, portanto, certo receio de que o padre renunciasse ao título de doutor em teologia e direito canônico, o que iria se contrapor ao propósito religioso de educar com base na racionalidade ocidental/colonial, ideia sustentada por uma população eurocêntrica, branca e cristã. Para Fanon (2003, p. 35-36), esta intenção religiosa revela uma prática maniqueísta, pois "o colonizador faz do colonizado uma quinta-essência do mal”, pois o indígena é declarado “impermeável à ética, aos valores”. É visto como inimigo dos valores e um elemento "deformador, capaz de desfigurar tudo que se refere à estética ou à moral, depositário de forças maléficas.

Outro exemplo do propósito religioso de educar com base na racionalidade ocidental/colonial pode ser observado na introdução e ressignificação do ritual de Encomendação das Almas na região de Oriximiná, o qual, segundo Costa (2012, p. 87), pode ser considerado uma herança dos tradicionais rituais de lamentação do mediterrâneo. A autora observa que a Encomendação das Almas chegou às Américas, mas precisamente ao Brasil, com o colonialismo português, por meio dos missionários jesuítas. No entanto, há registros de que ele também tenha sido introduzido na Amazônia pela atuação dos frades franciscanos de Portugal, da ordem dos Capuchos da Piedade, "que aportaram na região no final do século XVII, por volta do ano de 1693 , com objetivo de evangelizar os gentios" (SOARES, 2007, p.31).

Sobre esse processo de inserção da atividade missionária na região, Henrique (2013, p.137) comenta que a década de 1870, já no século XIX, ficou registrada como o início da retomada da atividade missionária na Amazônia, com a chegada de novos missionários. Segundo o autor, "foi um período de maior tensão, em função das pressões territoriais que os índios passaram a sofrer depois da navegação a vapor no rio Amazonas, do auge da coleta da borracha e demais produtos silvestres, principalmente às margens do rio Tapajós". Nesse processo, as desigualdades e as injustiças sociais se 
fortaleceram e, com elas, foi também fortalecida a ideia de que a população rural ocupava um lugar menor diante do discurso hegemônico de um modelo civilizatório.

Os moradores da região de Oriximiná afirmam que este ritual surgiu primeiro nas comunidades ribeirinhas do município, principalmente entre os habitantes do lago Sapucuá ${ }^{9}$, sendo gradativamente introduzido na zona urbana, o que pode ser confirmado pelo rezador Raimundo Eloi ao dizer: Quando eu me entendi, eles já rezavam. Rezavam lá no Iripixi ${ }^{10}$. Bem antes de 1971, isso já era comum no Cachoeiry ${ }^{11}$.

Loureiro (1995, p.30) observa que a população amazônica procura cultivar ao máximo a sua cultura, a qual está "mergulhada num ambiente onde predomina a transmissão oralizada”. O autor explica que essa cultura de transmissão oralizada reflete a relação do homem com a natureza e se apresenta imersa numa atmosfera em que o imaginário privilegia o sentido estético da realidade cultural. Mesmo diante das históricas tentativas de silenciamento dos saberes produzidos no universo amazônida, esta cultura sobrevive na dinâmica das práticas resultantes das experiências sociais e da criatividade de seus habitantes.

A exemplo disto, Figueira (1995) descreve alguns aspectos importantes do ritual de Encomendação das Almas. Ele relata que a Companhia, nome pelo qual o grupo de rezadores era conhecido na zona rural do município, saía do cemitério de determinada comunidade, seguia pelas margens dos rios e lagos até chegar ao porto de uma casa, onde reiniciava sua lúgubre reza, uma mistura de português arcaico com o latim. Observa ainda que a cantoria "é triste e sentimental, calando profundamente o coração dos que a escutam. É admirável a harmonia das vozes, sabendo-se que aqueles homens jamais tiveram conhecimento de qualquer princípio de música” (FIGUEIRA, 1995, p.32).

Ainda hoje há grupos de rezadores que mantém o ritual na zona urbana de Oriximiná. Estes são formados por seis ou sete senhores que, vestidos de branco e portando panos igualmente brancos sobre as cabeças, reúnem-se à meia-noite da Quartafeira de Trevas, no cruzeiro do cemitério, para saudar as almas com orações tristes, entoadas por diversas vezes. As preces são destinadas às almas benditas, mas

${ }^{9}$ Lago do município de Oriximiná onde residem várias comunidades ribeirinhas.

${ }^{10}$ Lago que avança o município pela sua zona sul.

${ }^{11} \mathrm{O}$ rio Cachoeiry liga o Trombetas, pela sua margem direita, com o rio Amazonas. Segundo os moradores que povoam as suas margens, antes, era um pequeno furo que foi alargado pelas correntezas do Amazonas. 
principalmente àquelas que estão em pecado mortal, que estão no purgatório, às almas cativas ou àquelas mais necessitadas.

Ao caracterizar os grupos de rezadores de Oriximiná, Loureiro (1995) descreve-os como grupos de folia ao estilo luso-brasileiro, quando pessoas invocavam perdão e piedade a Deus pelas almas condenadas. As almas condenadas são aquelas cujos corpos morreram em pecado mortal, sem arrependimento e sem o acolhimento ao amor misericordioso de Deus. Tratam-se daqueles que não se submetiam às excessivas ordens do clero e, por isso, eram considerados heterodoxos para Igreja, pois não se arrependiam em vida e nem acolhiam a misericórdia Divina, "preferindo o pecado", segundo a Igreja. As almas condenadas ao inferno, portanto, às quais é invocado o perdão e piedade a Deus, são aquelas deliberadamente em estado de "auto-exclusão" da comunhão com Deus e com os bem-aventurados.

Segundo Costa (2012, p.17),

Essa característica de salvação das almas em sofrimento descrita por Vovelle (2010) pode ser encontrada em ritos fúnebres de Encomendação das Almas dos mortos ocorridas em várias regiões brasileiras. Segundo Passarelli (2007), a Encomendação das Almas realizadas no Brasil, acontece por meio de orações que possuem objetivo de intermediar perante Deus e as almas Benditas a salvação dos mortos que estão em pecado mortal. Paralelo a essa intenção de salvar as almas do purgatório encontram-se indícios de que as orações realizadas pelos vivos tem o propósito de obter o salvamento das suas próprias almas quando estiverem diante da morte.

Como forma de conservar a tradição dos antepassados, os rezadores rezam nas casas das pessoas (geralmente parentes) que solicitam a oração, o que se dá por meio da colocação de uma vela solitária acesa em frente à moradia, símbolo da encomenda, como faziam seus predecessores nas comunidades da zona rural. O senhor Antônio Roque, chamado "padre" pelos outros componentes mais antigos do grupo, assim descreve os procedimentos gerais do ritual:

Ele começa quarta-feira Santa, às oito horas da noite. E continua na quinta-feira, finalizando a meia-noite de sexta-feira. Nós preferimos rezar nas casas, mas há outros rezadores que rezam nas esquinas das ruas. Antigamente as pessoas tinham medo de nosso ritual, hoje eles já vêem de perto (Antônio Roque).

A reza sempre causou certo medo à população, e isso é observado no recolhimento dos moradores mais idosos durante as orações, ao mesmo tempo em que desperta a curiosidade dos mais novos. Costa $(2012$, p.22) observou que o "ato de se encomendar 
as almas persuade, educa e previne os vivos para os ideais cristãos de solidariedade e caridade com o próximo esteja ele vivo ou morto"; além disso, "ensina a ter respeito com as tradições culturais e a valorizar os idosos como mantenedores da tradição e perpetuadores do ritual pela oralidade". Tratam-se de grupos de rezadores que entoam um canto triste em diversas alturas, com entonações graves e estendidas, como se revelassem um grupo de pessoas inconsoladas a pedir perdão humildemente. São cantos enigmáticos que paralisam e silencia quem os ouve, propiciando um momento de reflexão interior que imobiliza qualquer outro sentimento de alegria naquele lastimoso instante.

Os longos anos de convivência com os Rezadores de Almas na cidade de Oriximiná nos permitem descrever algumas histórias, decorrentes desse ritual, contadas por pessoas e transmitidas oralmente através dos tempos. Há, por exemplo, a superstição de não poder olhar para trás no momento em que eles estiverem rezando. Se tal fato acontecer, o desrespeitoso enxergará corpos em decomposição. É uma espécie "do interdito do olhar para traz", como na história cultural de tantos outros povos, que se misturou com fatos reais e históricos naquele contexto. Esta relação pode ser observada, por exemplo, no retorno ritual de Orfeu do inferno, ao resgatar das trevas Eurídice, a bem-amada; ou, na tradição bíblica, a fuga de Sodoma e Gomorra na hora da destruição (LOUREIRO, 1995, p. 160).

Conforme pesquisa realizada pelo Instituto de Artes do Pará (IAP) para documentar as chamadas liturgias ribeirinhas, a liderança das rezas, que são descritas em forma de ladainha, é do rezador que faz a primeira voz. Este recebe dos demais componentes do grupo a denominação de "padre", mesmo sem a permissão da Igreja Católica, uma vez que esta instituição se ausentou do ritual já algum tempo, devido, provavelmente, a utilização de bebidas alcoólicas pelos participantes.

Os rezadores justificam a utilização de bebidas durante o ritual pela necessidade de enfrentar o frio da madrugada e estimulá-los nas caminhadas, haja vista que após a saída do cemitério, as comitivas dirigirem-se às diversas casas para onde são solicitadas as rezas. A respeito das bebidas, o senhor Raimundo Eloi explica que eles bebem "um pouco de mangarataia para aliviar a dor de garganta nas noites frias. [...] Somente depois de meia-noite é que podemos beber". E complementa: "Nós não bebemos quando estamos rezando, a não ser a mangarataia”. Assim, na noite de Sexta-feira Santa, as equipes rezam em frente à Igreja, numa espécie de saudação, deslocando-se em seguida (pouco antes da meia-noite) ao cemitério para a última sessão de rezas, 
simbolizando a devolução das almas à necrópole, ação que encerra o ritual (IAP, 2006, p.03). No início e no final das orações é soada uma campainha, marcando o começo e encerramento do ritual de devoção em cada dia.

Mesmo que este não seja o objetivo do texto, cabe observar que, pelo viés educativo, como fez Albuquerque (2012) na obra "Beberagens indígenas e educação não escolar no Brasil colonial", as beberagens podem ser vistas, "prioritariamente, como acontecimentos educativos na medida em que faziam circular um conjunto de saberes. Para a autora, "É, portanto, a dimensão educativa que demarca esta diferença" (ALBUQUERQUE, 2012, p. 43). A autora destaca que os missionários católicos "foram extremamente hábeis em decifrar o poder que tinham as beberagens no ajuntamento e coesão social entre os índios". E observa que foi essa consciência, bem como o potencial educativo envolto nesse processo que provocou a "hostilização dessas práticas, vistas como obstáculo ao próprio projeto pedagógico da Igreja de catequização e conversão das almas.

\section{Educação escolar, saberes culturais e práticas educativas dos Encomendadores de Almas}

Entre os grupos que praticam o ritual de Encomendação de Almas em Oriximiná, optou-se por entrevistar aquele considerado pela comunidade como o mais conservador. Foram entrevistados os dois rezadores mais idosos do grupo. O rezador Antônio Roque, chamado padre ${ }^{12}$ pelos demais, possui 75 anos, estudou até a segunda série do ensino fundamental, nasceu na zona rural e depois de adulto mudou-se para a cidade. O rezador Raimundo Eloi, chamado de japonês devido as fortes feições orientais, possui 76 anos, estudou até a quarta série, também nasceu na zona rural e depois de adulto mudou-se para a cidade.

As entrevistas realizadas com os rezadores ajudaram a desvelar e a provocar interfaces entre o ritual e os sujeitos nele engajados, na conjuntura do discurso. As falas evidenciaram os significados que eles atribuem à escola e as estratégias que desenvolvem para resguardar seus saberes. No que se refere à preocupação com a manutenção do ritual, observou-se que a própria história contada acerca de como se tornaram Rezadores de Almas mostra a importância que esta manifestação cultural

\footnotetext{
${ }^{12}$ Esse tratamento o legitima como o principal e o mais respeitoso representante do grupo.
} 
adquiriu através dos tempos, pois revela a espontaneidade e a seriedade envolvidos nesse processo, fato que pode ser comprovado no relato do senhor Raimundo Eloi:

Eu me tornei um rezador de almas no Irixipi, em 1971. Foi meu primo Felipe que me convidou. Ele perguntou se eu gostaria de rezar para as almas. Eu respondi dizendo que queria. [...] Mas, após certo tempo, o Felipe parou de rezar e o João Gomes passou a ser meu companheiro. Com a morte de João Gomes, depois de um longo período de devoção, foi que mudei do Iripixi para a cidade. Aqui, fui convidado pelo Antônio Roque. Nós já estamos rezando há uns seis anos (Raimundo Eloi).

Como se pode verificar, nem o tempo ou a distância dos lugares de origem fez com que o pequeno grupo deixasse de rogar piedade a Deus pelas almas condenadas. A sucessão na família constitui uma forma de garantir que o ritual se mantenha através dos tempos, para que os saberes adquiridos pelos antepassados sejam salvaguardados como um bem precioso, conforme expressa o senhor Antônio Roque:

Eu aprendi a rezar com meu pai. Escutava ele fazer orações na Semana Santa e, aos poucos, fui gravando-as em minha mente. Em 1961, quando ele faleceu, eu já sabia tudo. Antes que ele morresse eu já sabia, mas ele era o rezador. Um ano após sua morte foi que o seu grupo me procurou (Antônio Roque).

$\mathrm{Na}$ família do senhor Antônio Roque ser rezador é um compromisso, uma responsabilidade vitalícia. É por isso que, mesmo com a força das transformações sociais este saber ainda resiste. O respeito, a atenção e o desejo de aprender aquelas orações que se repetiam continuamente nos ensaios ao lado do pai, fizeram com que ele guardasse na memória, com devoção, aqueles saberes culturais historicamente constituídos. A manutenção desse saber também se dá com a passagem do texto oral para o suporte escrito, para que os cantos sejam materializados e continuamente aprendidos, como explica o rezador Antônio Roque: "Eu procuro manter essa tradição para que ela não acabe [...] Se eu falhar, eles já saberão o que fazer. Eu dou as cópias para que eles aprendam as rezas (Antônio Roque).

A materialização do saber em escritos, portanto, traduz-se numa forma de resistência à marginalidade com que tais práticas foram tratadas no passado e num exercício contra hegemônico de poder, já que a erudição era um aspecto restrito aos clérigos nas sociedades rurais. Desta forma, é importante refletir sobre os mecanismos que legitimam e sancionam o poder a partir da compreensão do cotidiano e da realidade 
social. Este poder simbólico ${ }^{13}$ pode ser observado na falta de atenção e acolhimento da Igreja Católica à devoção religiosa praticada pelos Rezadores de Almas naquele contexto .

Portanto, o modus operandi do ritual evidencia que ele tem resistido e se mantido insubordinado às convenções e à autoridade da Igreja como uma estrutura de poder. Seus padrões e processos têm resistido, mesmo diante das lutas e do poder simbólico que tenta endemoniá-los para a população. Para os rezadores, há necessidade de que não se perca o padrão do ritual, o que pode provocar a perda da originalidade da reza, que é expressa em cânticos. Essa preocupação é destacada pelo rezador Raimundo Eloi ao dizer que “outro grupo não reza o 'Sacrário' e a 'Sexta-Santa'14 como nós rezamos. Só quem faz o "Misaré" é a nossa turma. Quem mais mantém nossa tradição nas rezas é o grupo do Iripixi. Eles rezam na mesma paginança”.

As relações e os conflitos estabelecidos ao longo da existência e manutenção do ritual naquele contexto fizeram com que este grupo mantivesse certa tradição nas rezas. Tratam-se de situações hostis vivenciadas, decorrentes do sistema simbólico construído pela Igreja Católica sobre eles, que os obrigou a expressarem a necessidade de respeito para com suas crenças, como destacado pelo rezador Antônio Roque:

Há muitos que participam, que levam a sério. Mas há outros tentam nos anarquizar, principalmente os mais jovens. E, por isso fomos obrigados a mudar nosso horário de reza. Antes, na zona rural, começávamos mais cedo. Aqui na cidade nós só podemos rezar a partir das dez horas, quando todos já estão se agasalhando. Tudo isso para evitar pedradas na cabeça. Ano passado fiquei muito aborrecido com um indivíduo e também peguei uma pedra para jogar nele. Penso que cada um deve seguir o seu caminho (Antônio Roque).

É possível perceber na fala do rezador certo tom de denúncia e revolta, haja vista que ele se percebe ameaçado, oprimido e castigado em decorrência da intolerância e desrespeito para com seu o saber. A mudança de horário para o início do ritual já é um prenúncio do que poderá acontecer com essa manifestação religiosa, se ainda persistir a indiferença das instituições sociais para com a diversidade no município. Imbernón (2000, p.84) destaca que a não-diversidade já não reflete apenas aquela "anedota" de pequenos confrontos na rua ou nos pátios das escolas, entre culturas diversas, mas

${ }^{13}$ Conceito desenvolvido por Bourdieu (1989, p.7-8), o "poder simbólico" se abriga e decorre das relações sociais de dominação e de resistências às formas e conteúdos de dominações e subalternizações, típicas das operações humanas.

${ }^{14}$ Nomes de dois cânticos. 
assume características de verdadeira tragédia e de vergonha, o que para ele pode se dar por um racismo induzido, pela pobreza e marginalização, ou ainda pela ideologia.

As atitudes desrespeitosas dos mais jovens, para o rezador Antônio Roque, caracterizam-se como práticas de perversidade e intolerância. O julgamento hostil e a indiferença, portanto, refletem a ignorância e apontam a necessidade de desvelar esses saberes subsumidos pela negligência, pela frieza com que são tratados. McLaren (1997) chama atenção para os tempos de ceticismo que vivemos, tempos estes marcados por relações sociais de desconforto e desconfiança que clamam por uma pedagogia crítica, ou seja, que ensine para uma cidadania híbrida e para a solidariedade multicultural.

O rezador Raimundo Eloi também denuncia as mesmas práticas de desrespeito. Para ele, "Não há mais respeito! Eles nos zombam, gritam e nos agridem com palavras, desnecessariamente. Nós temos cumprido nossa penitência e eles hão de cumprir a deles do jeito que merecem! (Raimundo Eloi). Este depoimento nos remete a Touraine (2004), ao dizer que o apelo à dignidade de si mesmo e do outro não constitui um universo de valores, mas somente de protestos e indignação. Para o autor, a fragilidade do sujeito implica na força da sua luta contra aquilo que o ameaça. E é na ligação da experiência pessoal, diz ele, com a ação coletiva que se acham as chances do sujeito sobreviver aos ataques das suas pulsões adversárias.

Uma análise crítica dessa realidade pode ser o primeiro passo para entrever as contradições que ainda persistem sob os discursos em favor da diversidade. Nesse sentido, acredita-se que as instituições educativas poderão ensinar a administrar esses conflitos, com base no respeito para com a diversidade religiosa, afim de que sejam revertidos em novos saberes. Sobre esta questão, quando perguntado aos rezadores se as escolas têm feito algo para ajudar a manter a tradição do ritual de Encomendação das Almas no município, o senhor Antônio Roque disse que "a escola não tem muito interesse em manter nossa tradição". Fica evidente nesta fala a falta de atenção e valorização da instituição com relação àquilo que eles entendem como um ato de fé. Tal crítica dirigida à escola talvez possa revelar a percepção que o rezador possui desta instituição, haja vista que ela não cumpre com sua missão de educar e "preparar" os mais jovens para a boa convivência social.

Imbernóm (2000, p. 43) observa que para o senso comum a educação tende a ser compreendida como preparação para a sociedade, para a vida adulta, para o trabalho ou para seguir adquirindo cultura. Entretanto, para o autor, antes de qualquer coisa, a escola é uma possibilidade de viver a cultura, pois a educação prepara para participar do 
mundo na medida em que proporciona cultura. E isso, para ele, é o que dá forma a nossa presença diante dos bens culturais, aqui compreendidos como saberes.

Compreende-se, desta forma, que os rezadores cobram nova postura das instituições de ensino do município para com seus saberes, principalmente no que concerne ao respeito à diversidade religiosa, neste caso o ritual de Encomendação das Almas, cujo principal objetivo é suplicar a Deus o perdão às almas condenadas ao pecado. Trata-se, conforme Imbernón (2000, p. 92), de a escola estimular essa dignidade humana baseada na solidariedade coletiva e na consciência social.

Quando investigados de que forma a escola poderia ajudar na manutenção dessa cultura, o senhor Antônio Roque assim expressa:

Eu acho que a escola poderia nos ajudar, pois o que fazemos é um ritual de devoção a Deus e às almas. Mas ela nos ignora. Eu entendo que poderíamos ter uma boa relação com a escola. Ela poderia nos ajudar e procurar saber conosco como é que funciona nosso ritual. E isso poderia ser levado às salas de aula para que os alunos também adquiram esse conhecimento. Mas não se faz nada disso (Antônio Roque).

Chama atenção nesta fala a reflexão que se orienta pela troca de saberes, ou seja, o rezador entende que através da escola esta prática cultural poderia ser mais conhecida e respeitada, assim como ajudaria na perenidade do ritual. Ao serem inquiridos se alguma vez foram convidados por alguma escola para falarem de seus saberes e de suas práticas culturais, os rezadores Antônio Roque e Raimundo Eloi foram enfáticos: “Não. Nunca! Nunca nos procuraram!’. Tais relatos indicam que os muros das instituições escolares no município de Oriximiná estabelecem limites entre a escola e as manifestações mais representativas. Ou seja, nos currículos das escolas não há espaço para o ritual de Encomendação das Almas. Se assim o for, os rezadores de almas estão à margem da fé disseminada nas escolas, mesmo que a fé que eles professem seja também de piedade Deus pelas almas condenadas, conforme expressou o rezador Antônio Roque.

Desta forma, pode-se dizer que o ritual de Encomendação das Almas é ignorado e ainda não é considerado um saber que pode viabilizar práticas pedagógicas transformadoras, pois ainda não há espaço para este ritual no cotidiano da escola. Em contraposição, Imbernón (2000, p.85) observa que a participação da comunidade é imprescindível para tornar possível o trabalho no campo da diversidade, o que para ele só pode acontecer em um ambiente de comunicação aberto e flexível, adaptado ao 
contexto e que permita a livre expressão dos professores, dos alunos e dos membros da comunidade da qual faz parte.

Para tanto, é necessário a construção de espaços educativos e de práticas de ensino que respeitem as diferenças, onde seja viável a circulação dos saberes culturais historicamente estigmatizados, tendo em vista a circulação de outras culturas e a manutenção dos saberes tradicionais do próprio povo. A frase "Nunca nos procuraram!", quando os rezadores se referiam a um possível chamado da escola, foi seguida por um silêncio imaginativo, o que denota a necessidade de interação e respeito da escola para com os seus saberes.

\section{Considerações Finais}

Neste estudo, cujo objetivo foi verificar como os rezadores expressam a preocupação com a manutenção dos saberes e de suas práticas culturais, e qual a importância atribuída por eles à escola para a preservação desse ritual no município de Oriximiná, destacou-se o processo histórico, as formas de controle e repressão vivenciados pelos rezadores na Semana Santa, durante o ritual de Encomendação das Almas.

Mesmo que no Brasil a liberdade de crença e de livre exercício de cultos religiosos esteja garantida em lei, e que de certa já haja em alguns espaços o reconhecimento de diferentes matrizes religiosas como fenômenos presentes em diversas culturas e tradições, em Oriximiná ainda ocorrem manifestações de intolerâncias e desrespeito às diversidades culturais. Tais fatos são denunciados nos relatos dos rezadores, ao falarem do ritual de Encomendação das Almas.

A história desta manifestação religiosa no município mostra que a tradição oral possibilitou que o ritual resistisse e se mantivesse entre as famílias dos rezadores, o que se deu com a manutenção das orações entre os familiares e amigos mais próximos. Outra maneira de resistir à indiferença da Igreja e da escola deu-se por meio da materialização das orações em "cópias", como uma forma de garantir esse saber às futuras gerações. A sucessão de rezadores na família tem constituído também importante forma de garantir os saberes adquiridos pelos seus antepassados e salvaguardar a memória como um bem precioso.

Chama atenção o esforço dos rezadores para que este ritual não pereça. Eles têm procurado fugir das agressões e ofensas, seja adaptando-se a novos horários de iniciação 
e término do ritual, seja esquivando-se dos caminhos considerados por eles mais perigosos. A necessidade de respeito e tolerância para com seus saberes culturais é constantemente denunciada nas falas, principalmente quando se referem aos mais jovens. Os desrespeitos materializam-se em ferimentos físicos e morais, em insultos e ofensas. Mas até o momento não conseguiram embargar os rezadores de cumprirem a sua profissão de fé.

Destaca-se, no contexto do município de Oriximiná, a necessidade de reflexão crítica acerca das práticas educativas e culturais pautadas nos modelos hegemônicos, pois o direito às diferenças deve prevalecer em detrimento das posturas excludentes que se manifestam nos espaços sociais e educativos. Trata-se, portanto, de superar as atitudes repressoras, condenatórias e excludentes e resgatar nas escolas o espaço extraescolar para que seja possível a viabilização de práticas pedagógicas que celebrem a diversidade cultural, ao invés de reprimi-las.

\section{REFERÊNCIAS}

ALBUQUERQUE, M. B. B. Beberagens indígenas e educação não escolar no Brasil Colonial. Belém: FCPTN, 2012.

ANDRÉ, M. E. D. A. de. Etnografia da prática escolar. Campinas: Papirus, 1995.

ANDRÉ, M. E. D. A. Estudo de caso em pesquisa e avaliação educacional. Brasília: Liberlivros, 2005. p. 7-70.

BRASIL. Constituição Federal. Brasília, Gráfica do Senado, 1988.

Parâmetros Curriculares Nacionais: Secretaria de Educação - Ensino Fundamental. Brasília: 2000.

BOURDIEU, P. O Poder Simbólico. Lisboa: DIFEL/Rio de Janeiro: Bertrand do Brasil, 1989.

CASTELL’S, M. O poder da identidade. Tradução Klauss Brandini Gerhardt. São Paulo: Paz e Terra, 2001.

CHARLOT, B. Da relação com o saber: elementos para uma teoria. Porto Alegre: Artmed, 2000. 
COSTA, A.C. L. da. A Morte e a Educação: saberes do Ritual de Encomendação das Almas na Amazônia. 2012. 183 f. Dissertação (Mestrado em Educação) - Universidade do Estado do Pará (UEPA), Belém, 2012.

FANON, F. Os Condenados da Terra. Rio de Janeiro: Civilização Brasileira, 2003.

FIGUEIRA, A. J. W. Oriximiná. Rio de Janeiro: ACG, 1995.

GABATZ, C. Diversidade cultural e religiosa e os desafios para uma educação inclusiva. In: CONGRESSO INTERNACIONAL DAS FACULDADES EST, 1., 2012, São Leopoldo

Anais do Congresso Internacional da Faculdade EST. São Leopoldo: EST, 2012. Disponível em: < http:// http://anais.est.edu.br/index.php/congresso/article/viewFile/68/6>. Acesso em: $10 \mathrm{de}$ fevereiro de 2016.

GEERTZ, C. A interpretação das culturas. Rio de Janeiro, Zahar, 1973.

HALL, S. A identidade cultural na pós-modernidade. Rio de Janeiro: DP \& A, 2003.

HALL, S. A centralidade da cultura: notas sobre as revoluções culturais do nosso tempo. Educação \& Realidade, Porto Alegre, vol. 22, n. 2, jul./dez. 1997, p. 18.

HENRIQUE, M. C. Entre o mito e a história: o padre que nasceu índio e a história de Oriximiná. Boletim do Museu Paraense Emílio Goeldi. Ciências Humanas. 2015, v. 10, n. 1, p. 47-64, jan.-abr. 2015. Disponível em: <http://dx.doi.org/10.1590/198181222015000100003>. Acesso em: 10 de fevereiro de 2015.

HENRIQUE, M. C. A perspectiva indígena das missões religiosas na Amazônia (Século XIX). História Social, n. 25, p. 132-155, jul.-dez. 2013. Disponível em: <http://www.ifch.unicamp.br/ojs/index.php/rhs/article/view/1840>. Acesso em: $10 \mathrm{de}$ fevereiro de 2015.

INCONTRI, D; BIGHETO, A. C. Ensino Religioso sem Proselitismo. É Possível? São Paulo: Mandruvá, 2005.

IMBERnÓM, F. (Org.) A educação no século XXI: os desafios do futuro imediato. Porto Alegre: Artmed, 2000.

IAP, Instituto de Artes do Pará. Liturgias Ribeirinhas no $\mathbf{n}^{\mathbf{1}}$. Encomendação das Almas. Belém, 2006.

LOUREIRO, J. de J. P. Cultura Amazônica: uma poética do imaginário. Belém: Cejup, 1995.

LÜDKE, M; ANDRÉ, M. E. D. A. Pesquisa em Educação: Abordagens Qualitativas. São Paulo: EPU, 1986.

MCLAREN, P. Multiculturalismo crítico. São Paulo: Cortez, 1997. 
MCLAREN, P. Rituais na escola: em direção a uma economia política de símbolos egestos na educação. Petrópolis-RJ: Vozes, 1991.

MORAES, M. C. O paradigma educacional emergente. Campinas-SP: Papirus, 1997.

MOREIRA, A. F. B.; CANDAU, V. M. C. Educação escolar e cultura(s): construindo caminhos. In: Educação como exercício de diversidade. Brasília: UNESCO, MEC, ANPEd, 2005. 476 p.

O’DWYER, E. C. Os quilombos e as fronteiras da Antropologia. Antropolítica:

Revista Contemporânea de Antropologia e Ciência Política, Niterói: EdUFF, n. 19, p. 91-111, 2007. Disponível em:

<http://www.uff.br/antropolitica/revistasantropoliticas/revista_antropolitica_19.pdf

$>$. Acesso em: 10 de fevereiro de 2015.

SACRISTÁN, J. G. A construção do discurso sobre a diversidade e suas práticas. In:

ALCUDIA, R. et al. Atenção à diversidade. Porto Alegre: Artmed, 2002.

SANTOS, L. L. de C; LOPES, J. de S. M. Globalização, multiculturalismo e currículo. In: MOREIRA, A. F. B. (Org.). Currículo: questões atuais. 6. Ed. Campinas: Papirus, 1997. p. 29-38.

SOARES, M. P. A poética da morte no ritual dos Encomendadores de Almas no município de Oriximiná. 2007. 131f. Dissertação (Mestrado em Ciência da Arte) Universidade Federal Fluminense, Rio de Janeiro, 2007.

SOARES, M. P. O estudo da etnicidade no ritual dos 'Encomendadores de Almas' no município de Oriximiná. Interethic@: Revista de estudos em relações interétnicas, Universidade de Brasília, v. 14 n. 2, p. 1-12. 2010. Disponível em:

<http://www.periodicos.unb.br/index.php/interethnica/article/download/11130/7984>. Acesso em: 10 de fevereiro de 2015.

TOURAINE, A. Podemos viver juntos? Iguais e diferentes. Petrópolis - RJ: Vozes, 2004.

DREHER, M. História do Povo Luterano. São Leopoldo: Sinodal, 2005.

\section{Como referenciar este artigo}

CÂNCIO, Raimundo Nonato de Pádua.; ARAÚJO, Sônia Maria da Silva. Educação escolar, saberes culturais e práticas educativas dos rezadores de almas na Amazônia. Revista Ibero-Americana de Estudos em Educação, Araraquara, v. 11, n. 4, p. 18641884, 2016. Disponível em: <http://dx.doi.org/10.21723/riaee.v11.n4.8766>. E-ISSN: $1982-5587$.

Submetido em: dezembro/2013

Aprovação final em: julho/2016 